\title{
Low COVID-19 Associated Mortality in Developing Countries, Could it be the High Flavonoid and Antioxidant Diet?
}

\author{
Mohammad Khalid* \\ Department of Medicine, King Faisal Specialist Hospital and Research Centre, Riyadh, Saudi Arabia
}

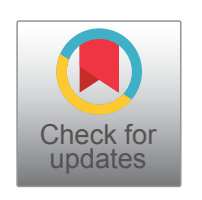

\section{Perspective}

Since the start of Coronavirus disease 2019 (COVID-19) infection, a significant scenario has emerged that is the difference in the severity of morbidity and mortality being much less in the developing countries compared to the European Union (EU), United States of America (USA) and the United Kingdom (UK). Several speculations have been made, childhood BCG vaccination acquired the most popular explanation but data does not confirm its role, very few have paid attention to different dietary habits, vegetarian and Mediterranean diet and high legumes diet in India, Arabia, Africa, while predominant meat, potato, bread and burgers diet in UK, USA and EU [1-3] (Figure 1).

To understand the diet may play a role in the severity of illness we should understand the pathophysiology of COVID-19.

The initial mode of the infection of the virus is thru lower respiratory tract, the virus is acquired through inhalation, the virus needs angiotensin-converting enzyme (ACE) receptor to gain access to pneumocyte, once in pneumocyte, it multiplies by incorporating into lysosomal RNA, it's now clear many cells including endothelial and red blood cells (RBC) have ACE receptors, after the lung involvement, virus very rapidly spreads to the other body organ systems the virus has an affinity to heme iron in hemoglobin most likely in few cycles of blood circulating in the lungs the whole blood RBC's get infected by the novel coronavirus $[4,5]$.

The virus causes generation of iron toxic radicals through abnormal heme metabolism that is mediated through Heme oxygenase-1 (HO-1), in this condition a large amount of free iron toxic radicals are released that cause severe cytokine inflammatory response syndrome (CIRS) which causes lung and other body organ system; liver, kidney, and heart damage. ACE receptors are found in the brain, kidneys and liver, virus also directly affect these organ systems, CIRS and endothelium infection initiates a severe hyper coagulopathic state that causes small and large vessels clots causing lung injury hepatic, renal failures and systemic thromboembolic process which is the main cause of morbidity and mortality in these patients $[6,7]$.
Generation of iron toxic radicals and CIRS is marked by rapid rise in inflammatory markers, ferritin, C-reactive protein (CRP), and liver enzymes, their high value is associated with severity of the disease [8-10].

It's now known that COVID-19 associated CIRS is in response to the virus affecting heme part of hemoglobin through HO1 pathway that causes generation of toxic free iron radicals that leads to CIRS and lungs and other body organ damage $[11,12]$.

Normal heme degradation is carried out by heme oxygenase-1 (HO-1) (Figure 2) which catalyzes the process and leads to the production of bile pigments, ferritin and Carbon Monoxide (CO) either excessive consumption of HO-1 possibly by the virus or dietary deficiencies mainly flavonoids that may cause a decrease in HO-1 that may lead to abnormal heme metabolism and production of toxic iron radicals, in a rare case report, a congenital deficiency of HO-1 causes almost similar coagulopathy as seen in COVID-19 with activation of coagulopathy pathway, endothelial damage, generation and deposition of iron in body organ systems and associated damage [13-15].

HO-1 production is dependent on the availability of flavonoids quercetins zinc and other dietary supplements, nutritional deficiency mainly flavonoids would cause low levels of HO-1 which then could lead to abnormal heme metabolism and generation of toxic iron radicals [16-18].

The natural substances containing quercetins and other flavonoids are legumes (lentils mainly green lentil also is

*Corresponding author: Mohammed Khalid, MD, Section of Pulmonary Medicine, Department of Medicine MBC 46, King Faisal Specialist Hospital and Research Centre, P O Box 3354, Riyadh 11211, Saudi Arabia, Tel: 966-1-4427493

Accepted: February 13, 2021

Published online: February 15, 2021

Citation: Khalid M (2021) Low COVID-19 Associated Mortality in Developing Countries, Could it be the High Flavonoid and Antioxidant Diet?. Arch Community Med 3(1):13-15 


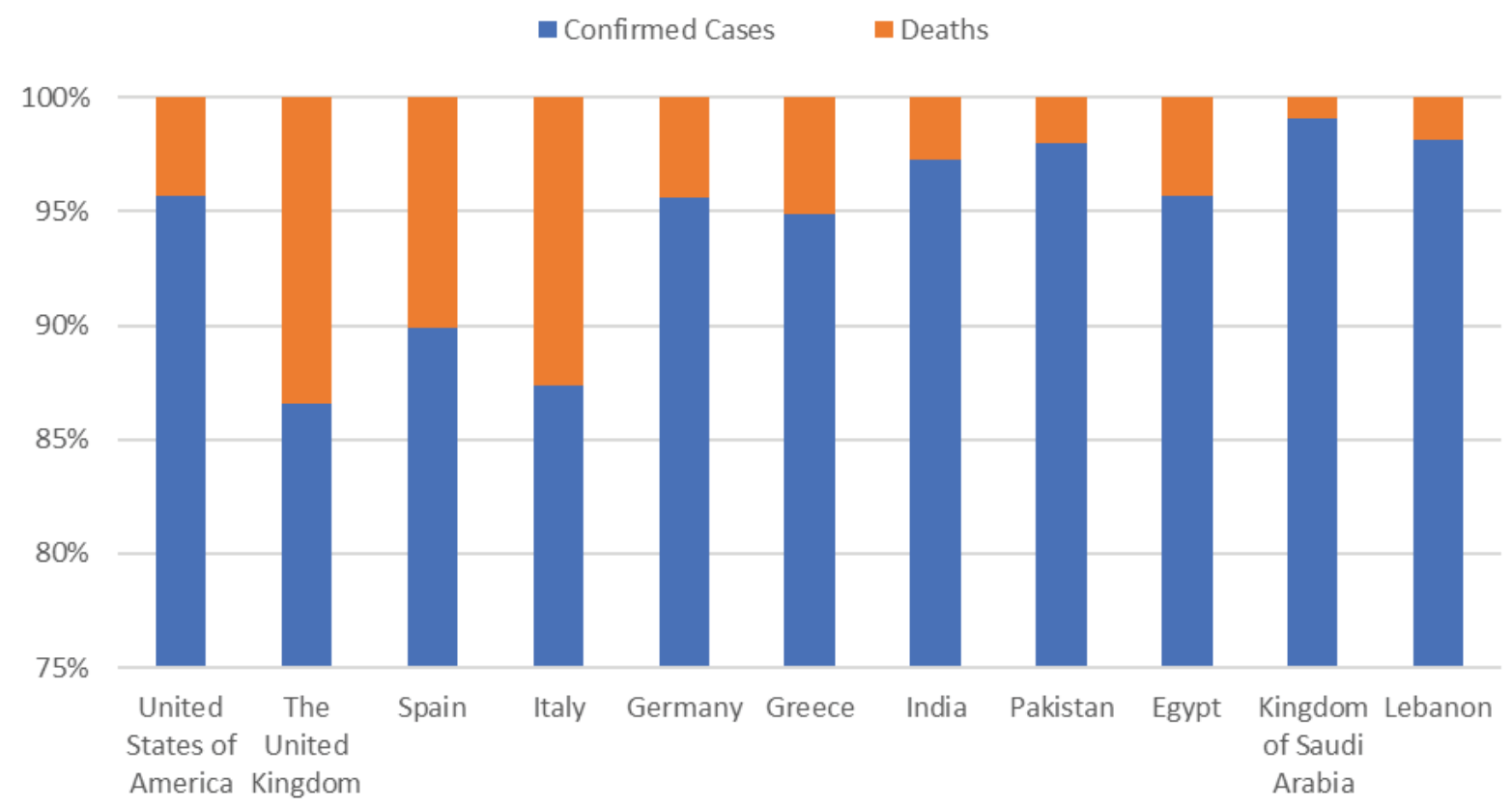

Figure 1: WHO reported coronavirus disease worldwide.

Image Source: https://covid19.who.int/ last updates July 7, 2020.

\section{Heme Degradation}

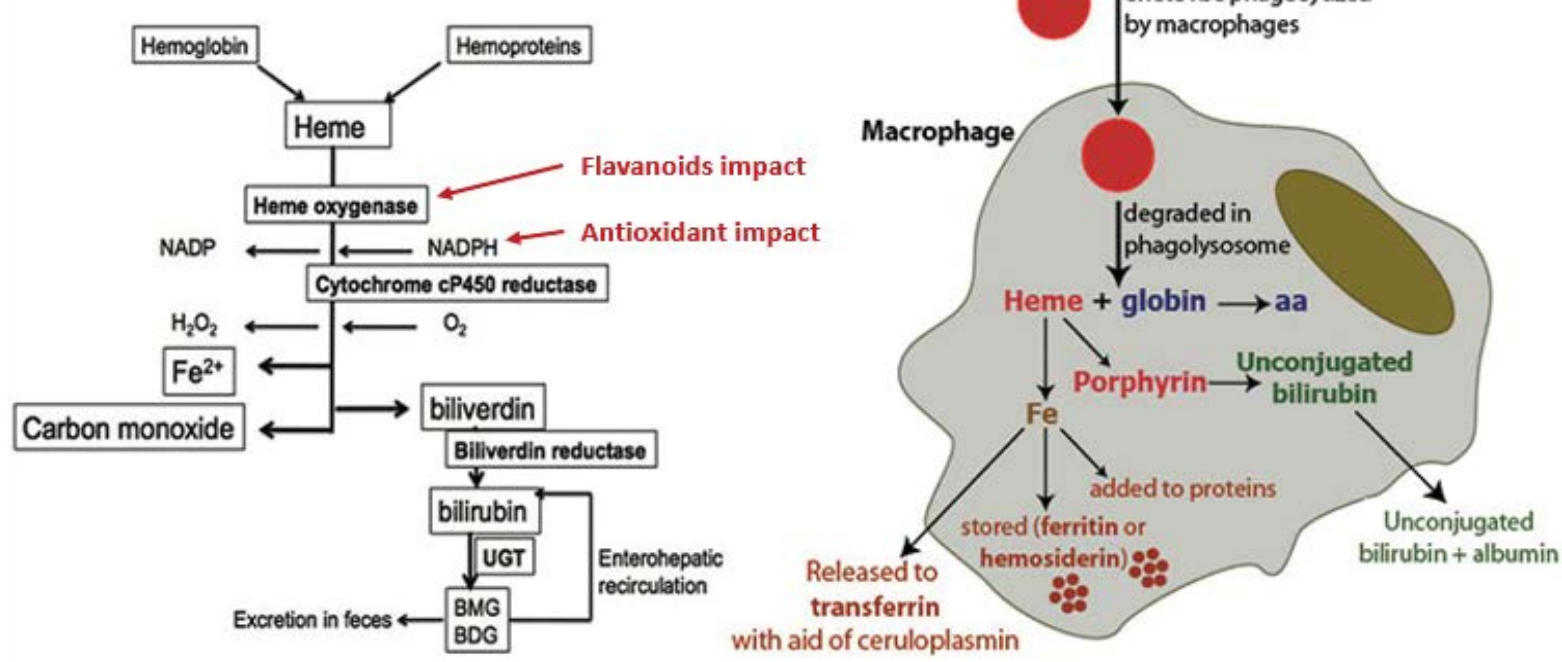

Figure 2: Heme degradation pathway.

Image Source: DOI: 10.3389/fphar.2012.00115.

known as mung lentil) red onions, fresh red pepper, green leafy vegetables, the skin of red grapes, apples and citrus fruits [19].

Asia, Africa, and Arab have a high lentil consumption and vegetarian diet, they also have low mortality from COVID-19 most likely due to high flavonoid and high antioxidant in their diet, while the EU, the UK, and the USA mainly meat, potato and meat burger based diet which is a low flavonoids and antioxidant diet. Elderly who are more vulnerable beside age and comorbidity also have multiple nutritional deficiencies that maybe a factor in increased severity of COVID-19 disease in elderly.

Level of hemoglobin in the blood may also play a role, developing countries may have low average hemoglobin levels hence less toxic iron radicals with COVID-19 infection and less severe CIRS and morbidity and mortality compared to average high hemoglobin values in EU and USA causing higher toxic iron radical generation and more severe CIRS [20]. Simi- 
larly, women with low average hemoglobin compared to men also may have less severe disease.

This may explain the disparity in disease severity and the difference in mortality in countries like India, Arabia, Africa, and the EU, the UK, and the USA.

The urgent need to increase dietary supplements that are high in flavonoids and anti-oxidants is to be recognized, which may help to prevent COVID-19 disease associated morbidity and mortality.

We propose following COVID-19 diet based on the availability of the high amount of flavonoids and rich in other essentials nutrients and anti-oxidants that is essential to maintain a healthy level of HO-1 and prevent the toxic iron radical generation and associated CIRS. We believe these measures will have a much better impact on mortality and morbidity in COVID-19 disease.

Legumes (lentils and beans), the skin of red grapes, red onion, green leafy vegetables, apples, citrus fruit for their high flavonoid content and antioxidant and zinc which play a dual role as antioxidant for suppression of CIRS and by preventing intracellular viral proliferation through activation of RNA polymerase. A daily dose of vitamin C $500 \mathrm{mg}$ - 1 gram a day, use of Omega 3 and Omega 10 supplements as antioxidant is recommended. As a role of melatonin as an antioxidant as well as its inhibitory effect on growth factor receptor signaling required for SARS-COV-2 replication is also considered to be beneficial [21].

A large study is needed to assess nutritional status and the impact of appropriate supplements on COVID-19 patients' morbidity and mortality.

\section{References}

1. Arts RJW, Moorlag S, Novakovic B, et al. (2018) BCG vaccination protects against experimental viral infection in humans through the induction of cytokines associated with trained immunity. Cell Host Microbe 23: 89-100.

2. Curtis N, Sparrow A, Ghebreyesus TA, et al. (2020) Considering BCG vaccination to reduce the impact of COVID-19. Lancet 395: 1545-1546.

3. Grant WB, Lathore H, McDonnell SL, et al. (2020) Evidence that Vitamin D supplementation could reduce risk of influenza and COVID-19 infections and deaths. Nutrients 12: 988.

4. Zhou P, Yang XL, Wang XG, et al. (2020) A pneumonia outbreak associated with a new coronavirus of probable bat origin. Nature 579: 270-273.

5. Gorbalenya AE, Baker SC, Baric RS, et al. (2020) Severe acute respiratory syndrome-related coronavirus: The species and its viruses - a statement of the coronavirus study group. bioRxiv.
6. Wenzhong L, Hualan L (2020) COVID-19: Attacks the 1-beta chain of hemoglobin and captures the porphyrin to inhibit human heme metabolism. ChemRxiv.

7. Liu W, Zhang S, Nekhai S, et al. (2020) Depriving iron supply to the virus represents a promising adjuvant therapeutic against viral survival. Curr Clin Microbiol Rep, 1-7.

8. Wang D, Hu B, Hu C, et al. (2020) Clinical characteristics of 138 hospitalized patients with 2019 novel coronavirus-infected pneumonia in Wuhan, China. JAMA 323: 1061-1069.

9. Guan WJ, Ni ZY, Hu Y, et al. (2020) Clinical characteristics of coronavirus disease 2019 in China. N Engl J Med 382: 1708-1720.

10. Shi H, Han X, Jiang N, et al. (2020) Radiological findings from 81 patients with COVID-19 pneumonia in Wuhan, China: A descriptive study. Lancet Infect Dis 20: 425-434.

11. Land WG (2020) Use of DAMPs and SAMPs as therapeutic targets or therapeutics: A note of caution. Mol Diagn Ther 24: 251-262.

12. Magrone T, Magrone M, Jirillo E (2020) Focus on receptors for coronaviruses with special reference to angiotensin-converting enzyme 2 as a potential drug target - A perspective. Endocr Metab Immune Disord Drug Targets 20: 807-811.

13. Vijayan V, Wagener FADTG, Immenschuh S (2018) The macrophage heme-heme oxygenase- 1 system and its role in inflammation. Biochem Pharmacol 153: 159-167.

14. Waza AA, Hamid Z, Ali S, et al. (2018) A review on heme oxygenase-1 induction: Is it a necessary evil. Inflamm Res 67: 579-588.

15. Yachie A, Niida Y, Wada T, et al. (1999) Oxidative stress causes enhanced endothelial cell injury in human heme oxygenase-1 deficiency. J Clin Invest 103: 129-135.

16. Luo M, Tian R, Yang Z, et al. (2019) Quercetin suppressed NADPH oxidase-derived oxidative stress via heme oxygenase- 1 induction in macrophages. Arch Biochem Biophys 671: 69-76.

17. Lin HY, Juan SH, Shen SC, et al. (2003) Inhibition of lipopolysaccharide-induced nitric oxide production by flavonoids in RAW264.7 macrophages involves heme oxygenase-1. Biochem Pharmacol 66: 1821-1832.

18. Nussler AK, Hao L, Knobeloch D, et al. (2010) Protective role of HO-1 for alcohol-dependent liver damage. Dig Dis 28: 792-798.

19. Panche AN, Diwan AD, Chandra SR (2016) Flavonoids: An overview. J Nutr Sci 5: e47.

20. Gretchen AS, Mariel MF, Luz MDR, et al. (2013) Global, regional, and national trends in haemoglobin concentration and prevalence of total and severe anaemia in children and pregnant and non-pregnant women for 1995-2011: A systematic analysis of population-representative data. Lancet Glob Health 1: e16-e25.

21. Tesarik J (2020) Melatonin attenuates growth factor receptor signaling required for SARS-CoV-2 replication. Melatonin Res 3: 534-537.

DOI: $10.36959 / 547 / 644$

Copyright: (C) 2021 Khalid M. This is an open-access article distributed under the terms of the Creative Commons Attribution License, which permits unrestricted use, distribution, and reproduction in any medium, provided the original author and source are credited. 